\title{
Relationship between the Power of the Two-Bit Cutting Body Rotation Drive of the Roadheader and Hardness of Broken Rock
}

\author{
Alexey Khoreshok ${ }^{1, *}$, Leonid Mametiev ${ }^{1}$, Alexander Tsekhin $^{1}$, and Andrey Borisov ${ }^{1}$ \\ ${ }^{1}$ T. F. Gorbachev Kuzbass State Technical University, Department of Mining Machines and \\ Complexes, Russia, 650000, Kemerovo, Vesennyaya st. 28
}

\begin{abstract}
The motion patterns of the cutting body of a roadheader with two kinematically connected reversible radial bits equipped with a disk tool on trihedron prisms are presented. The regularity of the disks motion under the action of forces applied to them is considered with allowance for the moments of inertia. The scheme of forming the depth of intrusion by the biconical disc tool of radial bits into the face rock strata is substantiated. The calculated dependences of the total torques $\Sigma M_{k}$ on the cutting body of the roadheader are obtained from the angle $\rho$ of the bits rotation, taking into account the contact strength $P_{k}$ of the rock strata to be broken. The calculation is made of the power of the rotation drive of the two-bit cutting body with a disk tool on trihedral prisms in breaking the rock strata in the range of strength characteristics for the mines of Kuzbass.
\end{abstract}

\section{Introduction}

In the technological process of a mining enterprise, development of mine workings is the most important link as the effective operation of the entire mining complex largely depends on its rate and quality $[1,2]$. In this connection, the adequacy of the design and operating parameters of the roadheaders' cutting tools to the operational mining and geological conditions is the main factor affecting the performance indicators of the process of underground mine working development [3-5].

The practice of underground mining has shown that rocks with strength of $f=6-10$ and high abrasiveness are advisable to be broken with the help of disk tools that have higher strength, wear resistance and less dust generation in comparison with the cutters [6-8].

The use of disk tools on the cutting bodies of roadheaders of selective action is a poorly studied issue and requires special studies on rock cutting, crushing and loading in reversible operating modes $[9,10]$.

\footnotetext{
* Corresponding author: bau.asp@rambler.ru
} 


\section{Mechanism of disc tool interaction with the face}

The studies performed by scientists of the KuzSTU Department of Mining Machines and Complexes for the conditions of the mines of "SUEK-Kuzbass" were aimed at developing and determining the loading parameters of two kinematically connected reversible radial cutting bits equipped with a disk tool $[5,6]$.

A variant of the scheme for matching the constructive-kinematic parameters of two reversible radial cutting bits with a disk tool on trihedral prisms is shown in Fig. 1. Correct substantiation of constructive, kinematic and power parameters during operation of reversible bits at the development face allows us to combine the processes of cutting, crushing of oversized rocks and loading. [11-13].

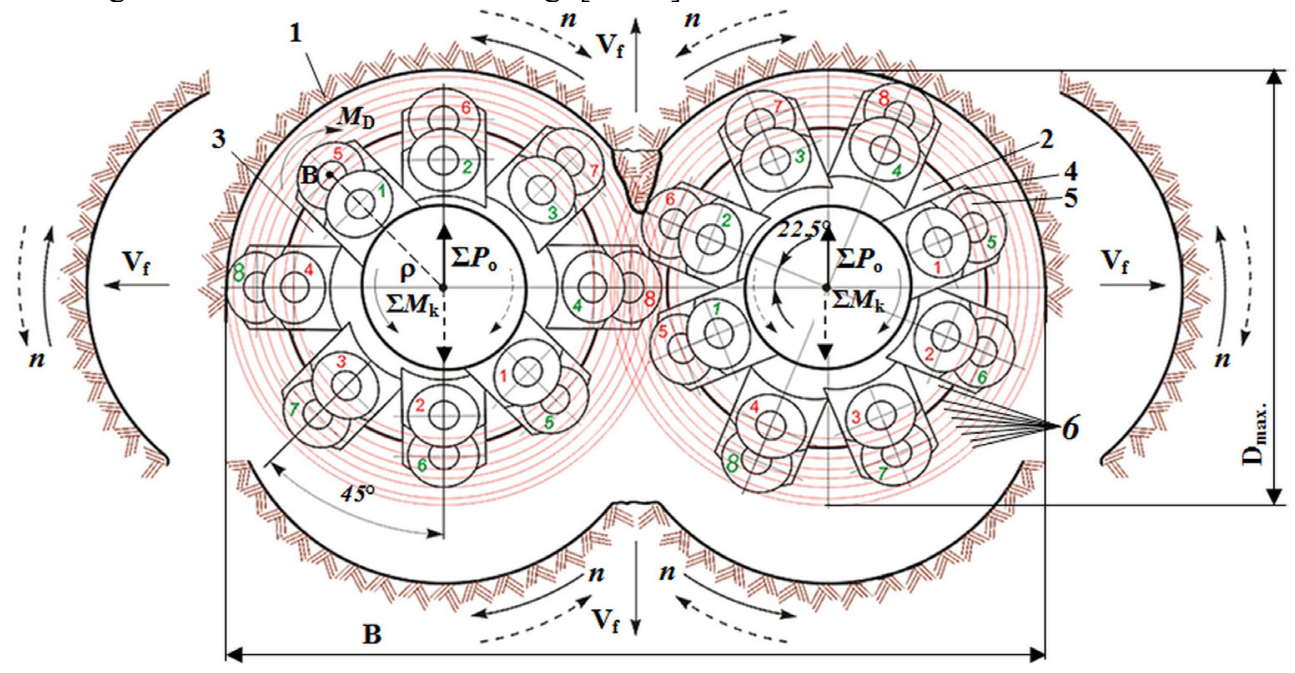

Fig. 1. Pattern of constructive units motion: 1 - cutting surface; 2 and 3 - radial left and right bits; 4 trihedron prizm; 5 - disc tool; 6 - a family of roll-over lines; B - cutting body width, m; $\mathrm{D}_{\max }-$ max. diameter of disc tool roll-over periphery, $\mathrm{m} ; \mathrm{n}-$ bit rotation speed, RPM; $\mathrm{V}_{\mathrm{f}}-$ cutter bit feed, $\mathrm{m} / \mathrm{min}$; $\Sigma \mathrm{P}_{\mathrm{O}}$ - total axial force, $\mathrm{kN} ; \Sigma \mathrm{M}_{\mathrm{k}}$ - total torque, $\mathrm{N} \cdot \mathrm{m}$.

As can be seen from Fig. 1, when interacting with the rock, the disk tools roll over eight circles with a step of destruction. Since the disk tools are installed on the bit in the form of two spirals, two disk tools roll over one circle.

Now we'll consider the patterns of their motion under the action of forces applied to them, taking into account the inertia. The left and right bits of the boom-type cutting body perform simultaneously both the rotational motion and the plane-parallel travel in the process of cutting the heading face. Disk tools installed on the bits roll over the face surface and rotate around their axes. Thus, the bit and the discs present a system possessing the kinetic energy.

Let us consider in more detail the patterns of a single disk tool motion with respect to a fixed coordinate system.

The dependence of torque $M_{D}$ on the angle of rotation $\rho$ will be sought using the Lagrange equation of the second kind. From the scheme of the bit and the disk tool shown in Fig. 1, it can be concluded that the bit and the disk tool perform a plane movement. In this case, the movement of bit 1 will be main and will be determined by two force elements: feed force $\mathrm{P}_{\mathrm{D}}$ and a pair of forces with torque $\mathrm{M}$. The motion of disk 2 will be dependent on the kinematics of the motion of bit 1 . Thus, the presented system of two bodies has two degrees of freedom and its description requires two generalized coordinates.

We choose the vertical travel $\mathrm{S}_{\mathrm{f}}$ and the angle of rotation $\rho$ of bit 1 as these coordinates. 
Then the system of Lagrange equations will have the following form:

$$
\begin{aligned}
& \frac{\mathrm{d}}{\mathrm{dt}}\left(\frac{\partial \mathrm{T}}{\partial \omega_{1}}\right)-\frac{\partial \mathrm{T}}{\partial \rho}=\mathrm{Q}_{1} \\
& \frac{\mathrm{d}}{\mathrm{dt}}\left(\frac{\partial \mathrm{T}}{\partial \mathrm{V}_{\mathrm{f}}}\right)-\frac{\partial \mathrm{T}}{\partial \mathrm{s}_{\mathrm{f}}}=\mathrm{Q}_{2}
\end{aligned}
$$

where $\mathrm{T}-$ kinetic energy of the system of bodies, $\mathrm{J} ; \mathrm{V}_{\mathrm{f}}-$ feed speed, $\mathrm{m} / \mathrm{s} ; \omega_{1}-$ angular speed of the bit, $\sec ^{-1} ; \mathrm{Q}_{1}, \mathrm{Q}_{2}$ - generalized forces that correspond to generalized coordinates $\rho, \operatorname{rad}$ and $\mathrm{S}_{\mathrm{f}}, \mathrm{m}$.

Since torques $M$ and $M_{\mathrm{D}}$ have no effect on the translational travel $S_{\mathrm{f}}$, in the formula (1) it suffices to consider only the first of equations.

We express the kinetic energy of the system through the angular velocities of the bit and disk, then we obtain: $T=T_{1}+T_{2}$, each of which will be calculated by the Koenig theorem:

$$
\mathrm{T}_{1}=\frac{\mathrm{I}_{\mathrm{A}} \cdot \omega_{1}^{2}}{2}+\frac{\mathrm{m}_{1} \cdot \mathrm{V}_{\mathrm{f}}^{2}}{2}, \mathrm{~T}_{2}=\frac{\mathrm{I}_{\mathrm{B}} \cdot \omega_{2}^{2}}{2}+\frac{\mathrm{m}_{2} \cdot \mathrm{V}_{\mathrm{B}}^{2}}{2}
$$

where $I_{\mathrm{A}}, I_{\mathrm{B}}-$ inertia of the bit and the disc, $\mathrm{kg} \cdot \mathrm{m}^{2} ; \omega_{2}-$ angular velocity of the disc, $\mathrm{s}^{-1}$; $V_{\mathrm{B}}$ - velocity of point $B$ of the disc, $\mathrm{m} / \mathrm{s} ; m_{1}, m_{2}$ - weight of the head and the disc, $\mathrm{kg}$.

The moment of inertia of a homogeneous disk tool is determined relative to its center of mass located on the axis of its rotation

$$
\mathrm{I}_{\mathrm{B}}=\frac{\mathrm{m}_{2} \mathrm{r}^{2}}{2}
$$

When the disk tool interacts with the face, crescent chips are formed, so to determine the speed of point $\mathrm{B}$, we define the law of its motion with respect to the fixed coordinate system:

$$
\left\{\begin{array}{l}
\mathrm{x}_{\mathrm{B}}=\mathrm{x}_{\mathrm{A}}+[\mathrm{R}+\mathrm{h}(\rho)] \cdot \cos \rho \\
\mathrm{y}_{\mathrm{B}}=[\mathrm{R}+\mathrm{h}(\rho)] \cdot \sin \rho+\mathrm{s}_{\mathrm{f}}
\end{array}\right.
$$

where $h(\rho)$ - the law of variation of the crescent chip, $\mathrm{m} ; R$ - radius of the bit, $\mathrm{m}$; $\mathrm{x}_{\mathrm{A}}, \mathrm{y}_{\mathrm{A}}, \mathrm{x}_{\mathrm{B}}, \mathrm{y}_{\mathrm{B}}$ - coordinates of points $A$ and $B, \mathrm{~m}$.

Then the time derivatives

$$
\dot{\mathrm{x}}_{\mathrm{B}}=\dot{\mathrm{h}}(\rho) \omega_{1} \cos \rho-[\mathrm{R}+\mathrm{h}(\rho)] \omega_{1} \sin \rho \text { and } \dot{\mathrm{y}}_{\mathrm{B}}=\dot{\mathrm{h}}(\rho) \omega_{1} \sin \rho+[\mathrm{R}+\mathrm{h}(\rho)] \omega_{1} \cos \rho+\mathrm{V}_{\mathrm{f}},
$$

where $\dot{\mathrm{h}}(\rho)$ and then $\ddot{\mathrm{h}}(\rho)$ are the derivatives with respect to a variable $\rho$. The square of velocity of point $B$ after the transformations will be equal to

$$
\begin{aligned}
& \mathrm{V}_{\mathrm{B}}^{2}=\dot{\mathrm{x}}_{\mathrm{B}}^{2}+\dot{\mathrm{y}}_{\mathrm{B}}^{2}=[\dot{\mathrm{h}}(\rho)]^{2} \omega_{1}^{2}+[\mathrm{R}+\mathrm{h}(\rho)]^{2} \omega_{1}^{2}+ \\
& +2 \mathrm{~V}_{\mathrm{f}} \omega_{1}(\dot{\mathrm{h}}(\rho) \sin \rho+[\mathrm{R}+\mathrm{h}(\rho)] \cos \rho)+\mathrm{V}_{\mathrm{f}}^{2}
\end{aligned}
$$

To determine the angular velocity $\omega_{2}$ of the disk, we use the relation from the theory of plane motion: $\omega_{2}=V_{\mathrm{B}} / \mathrm{r}$, where $\mathrm{r}$ is the disk radius, $\mathrm{m}$. Substituting all the found velocities in formula (2), we find that the kinetic energy depends on the angle of rotation $\rho$ and the 
velocities $V_{\mathrm{f}}$ and $\omega_{1}: T=T\left(\rho, V_{\mathrm{f}}, \omega_{1}\right)$.

Calculating from this function the partial and ordinary derivatives, we obtain for the left-hand side of equation (1) an expression of the following form :

$$
\frac{\mathrm{d}}{\mathrm{dt}}\left(\frac{\partial \mathrm{T}}{\partial \omega_{1}}\right)-\frac{\partial \mathrm{T}}{\partial \rho}=\left(\frac{\mathrm{I}_{\mathrm{B}}}{\mathrm{r}^{2}}+\mathrm{m}_{2}\right) \cdot(\dot{\mathrm{h}}(\rho) \cdot \ddot{\mathrm{h}}(\rho)+[\mathrm{R}+\mathrm{h}(\rho)] \dot{\mathrm{h}}(\rho)) \omega_{1}^{2}
$$

Next, we find generalized work of pairs of forces that correspond to a possible travel $\delta \rho$ counterclockwise. We fix the translational motion of bit 1 . Then, the possible work at rotation of bit 1 by angle $\delta \rho$ and, as a consequence, when disk 2 rotates by angle $R / \mathrm{r} \cdot \delta_{\rho}$ is equal to:

$\delta A_{1}=M \cdot \delta \rho^{+} \delta \mathrm{A}_{1}=\mathrm{M} \delta \rho+\mathrm{M}_{\mathrm{D}} \frac{\mathrm{R}}{\mathrm{r}} \delta \rho$, from which the generalized force $\mathrm{Q}_{1}=\mathrm{M}+\mathrm{M}_{\mathrm{D}} \cdot \frac{\mathrm{R}}{\mathrm{r}}$, where $M$ and $M_{\mathrm{D}}$ - torques of the active pair of forces and the pair of reaction forces, $\mathrm{N} \cdot \mathrm{m}$.

Thus, from equation (1) we obtain the required dependence of torque $M_{D}$ on the angle of rotation $\rho$ :

$$
M_{D}=\left[\left(\frac{I_{B}}{r^{2}}+m_{2}\right) \cdot(\dot{h}(\rho) \cdot \ddot{h}(\rho)+[R+h(\rho)] \dot{h}(\rho)) \omega_{1}^{2}-M\right] \cdot \frac{r}{R} .
$$

To use formula (8), we find from the experimental data by the least squares method the equation of the relationship between the value $h$ and the angle of rotation $\rho$ (crescent chip), which will have the form

$$
h(\rho)=\left[-0.329 \rho^{2}+1.036 \rho+0.036\right] \cdot h_{\text {max }}, m,
$$

where $\rho$ is measured in radian in the interval $[0 ; \pi]$ correlation coefficient is equal to $\mathrm{R}^{2}=0.938$.

Then the derivatives from formula (8) are equal to $\dot{h}(\rho)=[-0.658 \rho+1.036] \cdot h_{\max }$ and $\ddot{\mathrm{h}}(\rho)=[-0.658] \cdot \mathrm{h}_{\max }$. Thus, in expression (8) the maximum degree of the polynomial will be equal to three.

In the interaction of the left and right bits with the rock, in addition to the total torques $\Sigma \mathrm{M}_{\mathrm{k}}$, the external load acts on them as the total axial forces $\Sigma P_{\mathrm{O}}$.

On the basis of many years of research [14-17], it was suggested to focus on these forces as the most important component of the external load on the disk tool.

The process of interaction of single disk tools of the right bit of the cutting body with rock (Fig. 2) is characterized by the fact that when the bit rotates with the disk tool, its blade is in contact with the rock only at $\rho=0-180^{\circ}$.

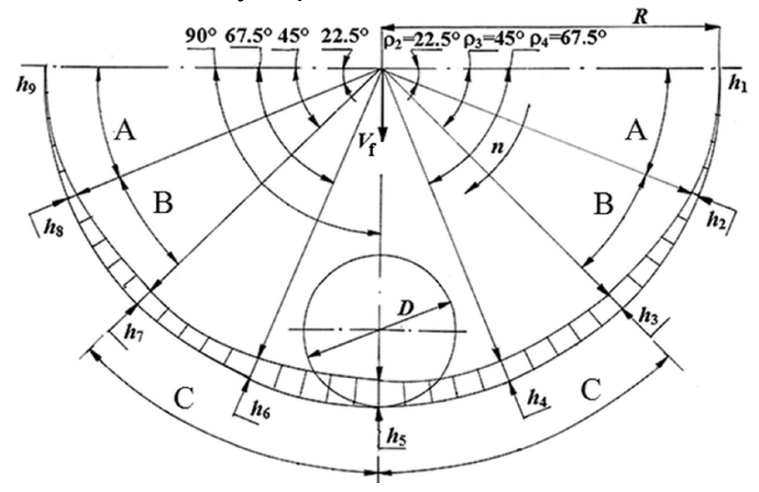

Fig. 2. The shape of the depth of the disk tool penetration into the face strata per one revolution of the radial bit. 
At $\rho=180-360^{\circ}$ there is no contact. At an increase of $\rho$ from $0^{\circ}$ to $90^{\circ}$, the depth of blade penetration $h$ in the rock increases: $h_{1}=0.1 h_{\max }, h_{2}=0.3 h_{\max }, h_{3}=0.6 h_{\max }, h_{4}=$ $0.8 h_{\max }$ and $h_{5}=h_{\max }$, and with an increase of $\rho$ from $90^{\circ}$ to $180^{\circ}$ the depth of penetration $h$ decreases: $h_{6}=0.8 h_{\max }, h_{7}=0.6 h_{\max }, h_{8}=0.3 h_{\max }$ and $h_{9}=0.1 h_{\max }$. This takes place in a conditionally control angular sequence with angles $\rho=0^{\circ} ; 22.5^{\circ} ; 45^{\circ} ; 67.5^{\circ} ; 90^{\circ} ; 112.5^{\circ}$; $135^{\circ} ; 157.5^{\circ}$ and $180^{\circ}$.

In general, for each disk tool, the surface of the imprint in the rock of the face with the depth of penetration has a crescent shape, the parameters of which are interrelated with the zones of the angular sectors of the disks location when the bits travel at a rotation frequency $\mathrm{n}$ and at feed to the face at a speed $\mathrm{V}_{\mathrm{f}}$ (Fig. 2).

In the peripheral zones A the penetration depth varies from $0.1 h_{\max }$ to $0.3 h_{\max }$ in the middle zones B from $0.3 h_{\max }$ to $0.6 h_{\max }$ and in the central zones $\mathrm{C}$ from $0.6 h_{\max }$ to $h_{\max }$.

\section{Modeling of torque and power}

In Fig. 3, Table 1 depicts the dependences of the total torques $\Sigma \mathrm{M}_{\mathrm{k}}$ on the two-bit cutting body on the angle of the bits rotation $\rho$ taking into account the contact strength $\mathrm{P}_{\mathrm{k}}$ of the rocks to be cut.

a

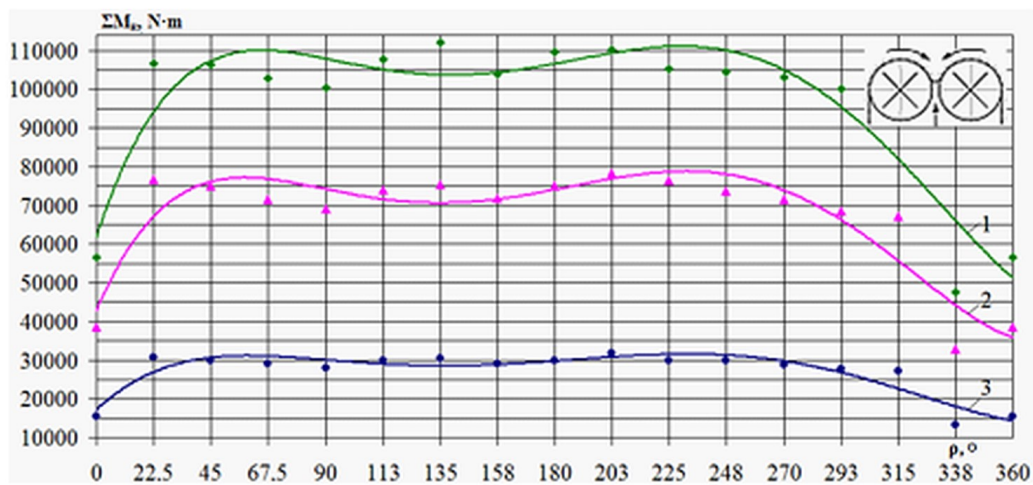

b

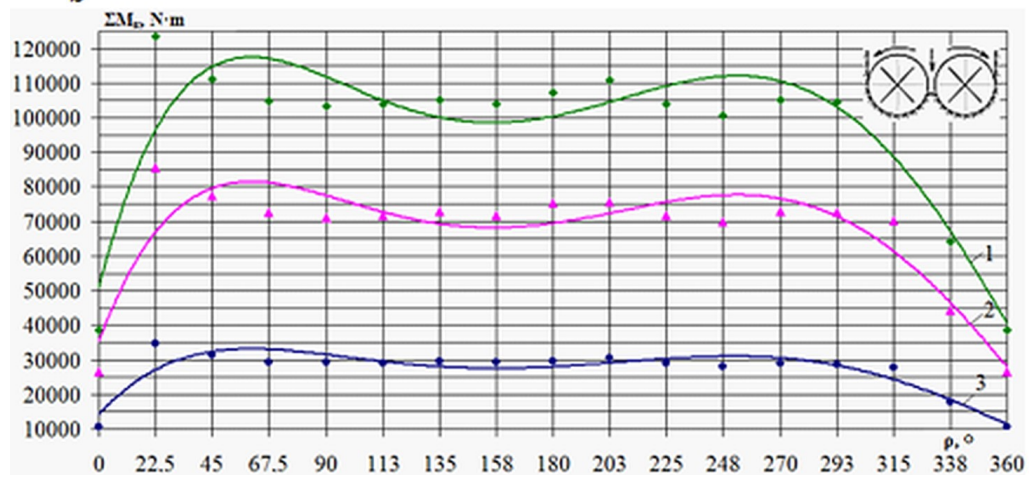

Fig. 3. Dependences of the torques $\Sigma M_{k}$ on the angle of bits rotation $\rho$ for the conditions $\left(1-\mathrm{P}_{\mathrm{k}}=1250 \mathrm{MPa} ; 2-\mathrm{P}_{\mathrm{k}}=860 \mathrm{MPa} ; 3-\mathrm{P}_{\mathrm{k}}=350 \mathrm{MPa}\right.$ ): (a) when the boom moves up and with the counter rotation of the bits from the top; (b) when the boom moves down and with the counter rotation of the bits from the bottom. 
Table 1. Dependences of torques $\Sigma \mathrm{M}_{\mathrm{k}}$ on the angle of bits rotation $\rho$.

\begin{tabular}{|c|c|}
\hline Dependences (Fig. 3, a) & $\mathbf{R}^{\mathbf{2}}$ \\
\hline $1-\Sigma M_{\mathrm{k}}=5 \mathrm{E}-07 \rho^{5}-0.0005 \rho^{4}+0.1881 \rho^{3}-29.871 \rho^{2}+2020.3 \rho+61858$ & 0.8384 \\
\hline $2-\Sigma M_{\mathrm{k}}=5 \mathrm{E}-07 \rho^{5}-0.0005 \rho^{4}+0.1634 \rho^{3}-24.845 \rho^{2}+1569.8 \rho+42721$ & 0.8562 \\
\hline $3-\Sigma M_{\mathrm{k}}=2 \mathrm{E}-07 \rho^{5}-0.0002 \rho^{4}+0.0634 \rho^{3}-9.764 \rho^{2}+626.29 \rho+17153$ & 0.8545 \\
\hline Dependences (Fig. 3, b) & $\mathbf{R}^{\mathbf{2}}$ \\
\hline $1-\Sigma M_{\mathrm{k}}=6 \mathrm{E}-07 \rho^{5}-0.0006 \rho^{4}+0.2477 \rho^{3}-41.818 \rho^{2}+2857.5 \rho+50797$ & 0.8317 \\
\hline $2-\Sigma M_{\mathrm{k}}=4 \mathrm{E}-07 \rho^{5}-0.0004 \rho^{4}+0.1722 \rho^{3}-29.081 \rho^{2}+1986 \rho+35169$ & 0.8296 \\
\hline $3-\Sigma M_{\mathrm{k}}=2 \mathrm{E}-07 \rho^{5}-0.0002 \rho^{4}+0.071 \rho^{3}-11.967 \rho^{2}+815.48 \rho+14157$ & 0.8364 \\
\hline
\end{tabular}

When the bit rotates, only half of the disk tools are in contact with the face, so the total torques acting on the disk tools of the right bit of the cutting body when it rotates counterclockwise is determined from the following expression:

$$
\Sigma M_{\mathrm{k}}=M_{\mathrm{k} 5}+M_{\mathrm{k} 1}+M_{\mathrm{k} 6}+M_{\mathrm{k} 2}+M_{\mathrm{k} 7}+M_{\mathrm{k} 3}+M_{\mathrm{k} 8}+M_{\mathrm{k} 4}, \mathrm{~N} \cdot \mathrm{m},
$$

where, for example, the torque on disc tool No. 1 is determined from the expression

$$
M_{\mathrm{k} 1}=P_{z 1} l_{1}, \mathrm{H} \cdot \mathrm{M} \text {, }
$$

where $P_{z 1}$ - the resultant of the distributed forces on the disk tool No. $1 ; l_{1}-$ arm of force $P_{z 1}$ relative to the axis of the bit of the boom-type cutting body, $\mathrm{m}$.

The drive power of a two-bit boom-type cutting body with disc tools on trihedral prisms was determined from expression:

$$
N_{\text {calc }}=\left(\Sigma M_{\mathrm{k} . \mathrm{b} \text { right }}+\Sigma M_{\mathrm{k} . \mathrm{b} \text { left }}\right) \cdot n / 9750, \mathrm{~kW},
$$

where $\Sigma M_{\text {k.b right }}$ - the total torque on the right bit, $\mathrm{N} \cdot \mathrm{m} ; \Sigma M_{\mathrm{k} . \mathrm{b} \text { left }}$ - the total torque on the left bit, $\mathrm{N} \cdot \mathrm{m} ; n-$ bits rotation frequency, $\mathrm{min}^{-1}$.

When the bit rotates from $\rho=0^{\circ}$ to $\rho=90^{\circ}$, the depth of the disc tool indent in rock increases from $0.1 h_{\max }$ to $h_{\max }$, and when it further rotates from $\rho=90^{\circ}$ to $\rho=180^{\circ}$, it decreases from $h_{\max }$ to $0.1 h_{\max }$. This explains the bell shape of dependences $\Sigma M_{\mathrm{k}}=f(\rho)$. When the bit turns to $180^{\circ}$, the parameter of the disc blade penetration in the rock $h$ varies from 1 to $10 \mathrm{~mm}$.

In Table 2, as an example, the values of the total torques $\Sigma M_{\mathrm{k}}$ and power $N_{\text {calc }}$ are given for different patterns of motion and rotation of the radial bits.

Table 2. Total torques $\Sigma M_{\mathrm{k}}$ and power $N_{\text {calc }}$ on a two-bit cutting body of a selective roadheader.

\begin{tabular}{|c|c|c|c|c|c|}
\hline \multicolumn{2}{|c|}{$\begin{array}{c}\text { Design } \\
\text { parameters }\end{array}$} & $\mathbf{\Sigma} \boldsymbol{M}_{\mathbf{k}}, \mathbf{N} \cdot \mathbf{m}$ & $\begin{array}{c}\boldsymbol{N}_{\text {calc }}, \mathbf{k W} \\
\mathbf{a t} \mathbf{n}=\mathbf{3 5} \mathbf{~ m i n}^{-\mathbf{1}}\end{array}$ & $\mathbf{\Sigma} \mathbf{M}_{\mathbf{k}}, \mathbf{N} \cdot \mathbf{m}$ & $\begin{array}{c}\boldsymbol{N}_{\text {calc, }}, \mathbf{k W} \\
\text { at } \mathbf{n}=\mathbf{3 5} \mathbf{~ m i n}^{\mathbf{1}}\end{array}$ \\
\hline \multirow{2}{*}{$\begin{array}{c}\mathrm{P}_{\mathrm{K}}, \\
\mathrm{MPa}\end{array}$} & 1250 & 112128 & 402 & 123367 & 442 \\
\cline { 2 - 6 } & 860 & 78245 & 280 & 85667 & 307 \\
\cline { 2 - 6 } & 350 & 31806 & 114 & 34831 & 125 \\
\hline
\end{tabular}

It is advisable to link the force and power parameters of two kinematically connected reversible radial bits equipped with a disc tool on trihedral prisms with the parameters of boom-type cutting bodies, in particular with their power, at the maximum values of $\mathrm{h}=8$ and $10 \mathrm{~mm}$. At lower $\mathrm{h}$ values, the drive of the boom-type cutting body of the roadheader will have a power margin. 


\section{Conclusion}

1. A constructive-kinematic design of a two-bit cutting body is proposed that provides a non-contact mode of rotation of trihedral prisms with disc tools in the central zone of intersection of their rotational motion patterns.

2. It is established that each of the disc tools, when buried and rolled over the face, forms grooves of a crescent shape, and the dependences of the calculated total torque on the mutually fixed angles of rotation of the cutting body bits in the range of contact strength $P_{\mathrm{k}}$ of the rocks being broken from $350 \mathrm{MPa}$ to $1250 \mathrm{MPa}$ are expressed as polynomials.

3 . The power ranges of the rotation drive of two-bit cutting bodies with a disc tool on trihedral prisms are determined, they are 114 to $402 \mathrm{~kW}$ when the boom moves up and the bits rotate in the counter rotation from the top, and they are 125 to $442 \mathrm{~kW}$ when the boom moves down and the bits are in counter rotation from the bottom at a range of the contact strength $P_{\mathrm{k}}$ of the rock strata to be cut from $350 \mathrm{MPa}$ to $1250 \mathrm{MPa}$.

4. An increase in the total power of the two-bit cutting body of the roadheader is noted when the boom moves down and the bits rotate in the counter direction from the bottom, compared with the upward movement of the boom and counter rotation of the bits from the top, which is caused by the combination of destruction, crushing and loading with partial transportation within the cutting width in the working area of the inter-bit space filled with products of rock destruction at the face of a development heading.

\section{Acknowledgement}

The results of the research were obtained with the financial support of the Ministry of Education and Science of Russia under Project No. 632 "Study of the parameters of technology and equipment for selection and development of innovative technical solutions for increasing the efficiency of mining and tunneling machines operation in Kuzbass."

\section{References}

1. A. A. Eremenko, V. A. Eremenko, A. N. Aleksandrov, V. N. Koltyshev, J. Min. Sci., 5, 878 (2014)

2. A. S. Kondratenko, V. V. Timonin, A.V. Patutin, J. Min. Sci., 1, 129 (2016)

3. A. Khoreshok, L. Mametyev, A. Borisov, A. Vorobiev 2014 Taishan academic forum project on mine disaster prevention and control. Chinese coal in the XXI century: Mining, green and safety, 177 (2014)

4. A. A. Khoreshok, L. E. Mametyev, A. Yu. Borisov, A. V. Vorobyev, IOP Conference Series: Materials Science and Engineering. 127, 012039 (2016)

5. L. Mametyev A. Khoreshok, A. Tsekhin, A. Borisov, E3S Web of Conferences, 21, 03005, (2017)

6. L.E. Mametyev, A.A. Khoreshok, A.M. Tsekhin, S.G. Mukhortikov, A.Yu. Borisov 2016 The 8th Russian-Chinese Symposium. Coal in the 21st Century: Mining, Processing and Safety, 233 (2016)

7. B. L. Gerike, V. I. Klishin, P. B. Gerike, J. Min. Sci., 3, 481 (2016)

8. B. L. Gerike, P. B. Gerike, V. I. Klishin, A. P. Filatov, J. Min. Sci., 5, 497 (2008)

9. B. L. Gerike, P. B. Gerike, A. P. Filatov, V. I. Klishin, J. Min. Sci., 6, 610 (2006)

10. P. B. Gerike, M. A. Belikov, J. Min. Sci., 2, 162 (2003) 
11. Z. L. Zhou, X. B. Li, G. Y. Zhao, Z. X. Liu, G. J. Xu, Appl. Mech. Mater., 52:54, 905 (2011)

12. K. Yang., Appl. Mech. Mater., 508, 159 (2014)

13. A. N. Zhang et al., Adv. Mater. Res., 791:793, 742 (2013)

14. X. H. Li, W. Du, Z. L. Huang, W. L. Fu, Appl. Mech. Mater., 127, 385 (2011)

15. B. Zhao, X. M. Zong, B. He, L.J. Zhang, Appl. Mech. Mater., 635:637, 358 (2014)

16. Y. Zhang, X. W. Wang, H. F. Liu, Appl. Mech. Mater., 487, 513 (2014)

17. F. H. Li, Z. X. Cai, Y. L Kang, Appl. Mech. Mater., 90:93, 2232 (2011) 